\title{
Implementing Pre-Emptive Managed Retreat: Constraints and Novel Insights
}

\author{
Judy Lawrence $^{1}$ (D) Jonathan Boston ${ }^{2} \cdot$ Robert Bell $^{3} \cdot$ Sam Olufson $^{1} \cdot$ Rick Kool $^{4,1} \cdot$ Matthew Hardcastle $^{5}$. \\ Adolf Stroombergen ${ }^{6}$
}

Published online: 3 July 2020

(C) The Author(s) 2020

\begin{abstract}
Purpose of Review Managed retreat will be inevitable where other adaptation options, such as protective structures or building restrictions, provide only temporary respite or are otherwise uneconomic, technically impractical or both. Here, we focus on the implementation of pre-emptive managed retreat, providing examples of how it can be sequenced, socialised and given the governance enablers necessary for implementation.

Recent Findings Ongoing sea-level rise during the twenty-first century and beyond poses huge adaptation challenges, especially for low-lying coastal and floodplain settlements. Settlements are already functionally disrupted from repetitive non-extreme flooding and research shows that sea-level rise will impact far more people, far sooner than previously thought, as more powerful storms, heavy rainfall and rising groundwater coincide with higher tides. To date, most examples of managed retreat have been post-disaster responses following damage and disruption. Pre-emptive managed retreat, by contrast, has yet to become a wellaccepted and widely practised adaptation response. Nevertheless, there are increasing examples of research and practice on how pre-emptive managed retreat can be designed, sequenced and implemented alongside other forms of adaptation within anticipatory forms of governance.

Summary The current state of knowledge about managed retreat is reviewed and critical insights and lessons for governance and policy-making are given. Several novel examples from New Zealand are presented to address some of the implementation gaps. Goals and principles are enunciated to inform long-term adaptation strategies.
\end{abstract}

Keywords Adaptation $\cdot$ Managed retreat $\cdot$ Sea-level rise $\cdot$ Dynamic adaptive pathways $\cdot$ Compensation $\cdot$ Anticipatory governance

This article is part of the Topical Collection on Progress in the Solution Space of Climate Adaptation

Judy Lawrence

judy.lawrence@vuw.ac.nz

1 New Zealand Climate Change Research Institute, Victoria University of Wellington, Wellington, New Zealand

2 School of Government, Victoria University of Wellington, Wellington, New Zealand

3 National Institute of Water and Atmospheric Research, Hamilton, New Zealand

4 Technical University of Denmark, Lyngby, Denmark

5 University of Auckland, Auckland, New Zealand

6 Infometrics, Wellington, New Zealand

\section{Introduction}

Ongoing sea-level rise during the twenty-first century and beyond poses huge adaptation challenges, especially for low-lying coastal and floodplain settlements. Already settlements are being functionally disrupted from repetitive nonextreme flooding [1], which will increasingly be exacerbated by more powerful storms, heavy rainfall and rising groundwater coinciding with higher tides. Research shows that sea-level rise will impact far more people, far sooner than previously thought [2]. Such climate change impacts pose many existential risks and governance challenges for coastal settlements globally, imposing large economic, social and psychological tolls [3-5]. In many flood-exposed places, the only sustainable long-term adaptation strategy will be managed retreat, due to the physical and affordability constraints of hard 
protection and the temporary nature of accommodation strategies [6].

Managed retreat is defined here to include planned retreat that removes people and their assets away from hazards such as sea-level rise and flooding-pre-emptively and permanently.

Removing or relocating well-established human settlements, however, is manifestly controversial, costly and time consuming. Aside from the physical difficulties, complex governance, legal, planning, distributional, cultural, place-attachment and funding issues arise [7-9]. What, for instance, is the nature of the 'social contract' between citizens and the state in the context of climate change adaptation? What are the demands of equity or fairness? What are the respective responsibilities of public authorities, businesses, communities and citizens [10, 11]? Besides such deeper philosophical issues, many practical policy questions emerge. How can managed retreat be implemented efficiently and effectively? What kind of public institutions and decision-making processes are needed? Who should pay for what and on what basis? And how should public funding be organised and administered to avoid moral hazard [12]?

To date, managed retreat has generally been reactive following major hazard events and their associated damage [13]. Strategic or pre-emptive examples are less common [6]. This suggests that post-disaster responses by governments are typically easier to implement politically than anticipatory, pro-active adaptation strategies [14-17], leaving aside managed coastal realignment in the UK that to date has not involved buildings and people [6]. Previous reviews of managed retreat $[18 ; 19]$ have also emphasised the many gaps in our current understanding of managed retreat as an adaptation option, its governance, funding and implementation issues. This paper focuses on these gaps and presents some lessons for implementing managed retreat.

First, we briefly explore the nature of managed retreat and its role to date as a climate change adaptation option.

Second, we identify the issues that managed retreat raises for affected communities related to governance, including planning, regulatory and funding processes.

Third, we outline the gaps in current knowledge about implementing managed retreat.

Fourth, we discuss adaptive decision-analysis tools relevant for implementation of managed retreat and present some novel applications from coastal and riverine settings in New Zealand.

Fifth, we examine institutional enablers for implementing managed retreat.

Finally, we enunciate a series of goals and principles to inform long-term adaptation strategies which incorporate managed retreat and suggest areas for further research.
Implementing Managed Retreat: A Stocktake

Managed retreat as defined here is a risk management strategy that tackles the exposure element of risk by removing people, buildings and infrastructure exposed to rising and more frequent coastal hazards $[6 ; 18]$ or flood hazards, with the opportunity to also address vulnerability by enhancing societal resilience. Abandonment and gradual voluntary movement of people away from the coast by attrition constitutes unmanaged retreat.

The international evidence highlights that managed retreat can be undertaken at various scales $[19,20]$. This can range from the relocation of buildings within property boundaries or to other locations, as well as the relocation of entire settlements. Managed retreat can be distinguished in other respects including $[8,18]$

- Whether it is ad hoc or part of a strategic policy framework (e.g. one designed to enhance sustainable development and improve societal wellbeing);

- Whether it occurs in conjunction with, or as an alternative to, the construction of major protective structures, beach nourishment or raising buildings, for example;

- Whether it is reactive and post-disaster (e.g. following a major storm event) or pre-emptive and anticipatory in character;

- Whether implementation relies entirely on voluntary measures by individuals and firms or includes elements of public compulsion;

- Whether public financial assistance is provided and, if so, what form this takes (e.g. compensation for property losses, subsidies for relocation expenses, the provision of alternative housing, investment in new infrastructure, funding for managing the vacated land); and

- Whether it involves a single tier or multiple tiers of government.

Retreat from existing areas of human settlement in response to coastal and flood hazards has been a feature of civilisation for millennia, but never before has retreat encountered the huge challenge from expensive assets and services fixed in place [21]. Until recently, retreat has been mostly unplanned and unmanaged, with little if any public assistance to address place-based attachment [9] or exposure of extensive publicly owned fixed assets and services. As a result of ongoing, accelerating sea-level rise [22] and flood hazards compounded from severe storms, seawater flooding, intense rainfall, rising groundwater and land subsidence, lowland coastal exposure is being exacerbated [23, 24].

Globally, there are now many examples of publicly coordinated or managed retreats in both pre- and post-disaster contexts, both voluntary and involuntary [18]. Cumulatively over the last three decades, approximately 1.3 million people 
in 22 countries have been relocated via managed retreat [18]. However, these examples are from all forms of geologic hazards (e.g. riverine flooding, earthquakes, landslides) and the resulting relocation of populations was generally not planned managed retreat [6]. Increasingly, the unmanaged and voluntary movement of people away from uninhabitable areas as climate change impacts intensify will focus attention on managed retreat as an adaptation option in the major deltas of the world and in cities where coastal inundation is already occurring, e.g. Miami, Lagos, Mumbai and Jakarta [4, 18, 25].

Notable examples of publicly funded pre-emptive managed retreat in coastal and riverine settings include the Delta programme in the Netherlands [26] and Twin Streams in Auckland, New Zealand [27]. Both involved making 'room for the river' and notably both had dedicated public funding available within a national institutional framework (i.e. the Delta Commission and a dedicated buy-back fund, respectively) and significant community engagement. The former is accompanied by a major pre-emptive beach nourishment programme ('Sand Engine') as a defence for the dikes and funded by the government [28].

The USA has some of the longest running publicly funded programmes for post-disaster protection and managed retreat [29]. These include post-event beach nourishment and rock revetments, and extensive buyouts of high-risk properties through well-established governance arrangements, planning processes and funding criteria. Co-funding across different tiers of government is the norm in the USA, albeit with the federal government bearing the largest proportion of the costs through FEMA. Increasingly, New Zealand local government is making provision for retreat funding, but to a limited extent and after significant floods where there is a history of flooding (e.g. Horizons Regional Council) [30].

Even fewer studies explore the broader philosophical and policy issues that enable the effective implementation of managed retreat, such as governance, regulation, institutional design and funding. Such matters include

- The allocation of decision-rights across the various levels of government;

- The selection and use of decision-analysis tools to guide decision-making;

- The design of planning processes to enable public participation and community engagement to address contestation and build understanding and buy-in;

- The criteria for assessing risk and setting thresholds for intervention;

- The design of public institutions to oversee the conduct and implementation of managed retreat;

- The principles for cost-sharing (e.g. for infrastructure costs);

- The provision of public compensation for property loss and damage;
- The case for pre-funding future adaptation costs;

- The design of dedicated funding mechanisms;

- The relationship between adaptation planning and routine spatial planning; and

- Mechanisms for minimizing moral hazard.

Furthermore, few studies go beyond local examples to compare and assess the different institutional frameworks operating in various countries for implementing managing retreat, whether pre-emptive or post hoc [8]. Those examples that do focus on managed retreat show that there is an uncoordinated range of approaches to funding that focus on shared funding between federal/national, regional and local agencies $[31,32]$. The literature gives only modest attention to the interface between private insurance and public funding [12], the funding arrangements for different kinds of public infrastructure, the principles informing compensatory arrangements, the handling of business disruption and the overall cost-effectiveness of the approaches adopted [8]. Yet, these issues are highly relevant before retreat becomes necessary. It is therefore timely to consider these issues now.

\section{Addressing Constraints to Implementing Managed Retreat}

Currently, few countries have the regulatory, planning and funding frameworks for effective responses to the current and projected impacts of climate change. Some jurisdictions (e.g. UK, New Zealand, Netherlands and Singapore) are however starting to improve risk management strategies, design new regulations and standards, improve land-use planning provisions and insurance policy settings, and build resilient and flexible designs for infrastructure and protective structures, such as nature-based approaches to adaptation. However, few countries (e.g. the Netherlands) have dedicated and systematic national-level policy frameworks dealing with the costs of climate change adaptation (e.g. who pays for what and on what basis). Most countries are much less well prepared.

Table 1 outlines some of the constraints currently inhibiting the development and application of pre-emptive managed retreat strategies building on previous literature [33]. The governance, political and planning issues identified in the table are well recognised in the relevant adaptation literature. For instance, community opposition to proposals for managed retreat is commonplace $[9,34]$ and the public's tolerance of risk is typically higher before a natural disaster than afterwards [14]. Against this, new risks can also be over-reacted to, while known risks are often under-responded to [35]. Many people have strong ties to their place of residence: it is, after all, their home. In the case of indigenous peoples, the threatened land may have been occupied for millennia and may be fundamental to cultural identity and practices [36]. On an economic 
Table 1 Constraints on implementation of managed retreat as an adaptation option and possible mitigation strategies

$\begin{array}{lll}\begin{array}{l}\text { Type of } \\ \text { constraint }\end{array} & \text { Stressors } & \text { Mitigation strategies }\end{array}$

\begin{tabular}{cl}
\hline Contextual & 1. Potential large scale of relocation of human settlements \\
issues & 2. Uncertainty over scale and timeframes of managed retreat \\
& 3. Limited understanding of available data and changing risk \\
profiles & \\
& 4. Limited capability and capacity to apply, appropriate \\
decision-making tools for managed retreat, e.g. Dynamic \\
Adaptive Planning Pathways \\
5. Disagreements (e.g. over risk thresholds and trigger points) \\
6. Limited availability, suitability and affordability of sites for \\
resettlement \\
issues \\
1. Weak and inconsistent political leadership, and a focus on the \\
short term \\
2. Failure to integrate managed retreat within strategic \\
policy-making frameworks \\
3. Uncertainty over allocation of responsibilities and decision-rights \\
for managed retreat between different levels of government \\
4. Limited coordinating capacity across key policy domains, e.g. \\
infrastructure, public services, spatial planning, funding of retreat \\
5. Limited institutional capacity for designing, negotiating, \\
engaging and implementing large-scale managed retreat
\end{tabular}

1. Strong attachment to place

opposition 2. Lower risk tolerance for new risks compared with experienced risks

3. Mistrust and rejection of expert risk assessments and advice

4. Community preference for protection over retreat and/or rejection of retreat strategies

5. Opposition to retreat from communities in and adjacent to hazard areas due to expected negative impacts on property and amenity values, and reduced public services

6. Uncertainty over level, forms, and eligibility for pubic compensation or other public assistance

7. Legal action to challenge retreat as an adaptation option

Planning 1. Inconsistent and inflexible application of planning rules and arrange- $\quad$ procedures that can address changing risk profiles with time

ments 2. Pressure from developers to continue coastal development

3. Inadequate provision for public participation in decision-making processes

4. Uncertainty over the timeframes for property buyouts and relocation

5. Poor management and use of the vacated land

Funding 1. Inadequate overall public resources for the scale of retreats issues required

2. Ad hoc and inconsistent funding arrangements that focus on funding post-disaster, rather than pre-emptive managed retreat

3. Sub-national governments often lack borrowing rights or have limited taxation options

4. Co-funding arrangements which add complexity and exacerbate delays

5. No pre-funding of the long-term costs of managed retreat

6. Political disagreement over public compensation for private losses

Equity issues 1. Low-income households disproportionately affected

2. Many low-income households cannot afford to relocate

3. Limited coverage of private insurance
1. Additional funding for decision-relevant adaptation-related research, data gathering and risk assessments

2. Investment in building capability and capacity for adaptation planning

3. Use of Dynamic Adaptive Planning Pathways, Real Option Analysis, scenario analysis, and serious games to improve understanding of the problem, adaptation options and for developing adaptive pathways

4. New processes to address and resolve disagreements

1. Stronger focus on anticipatory governance

2. Integration of managed retreat into all relevant strategic policy processes at the national and sub-national levels of government

3. Legislative or constitutional reforms to clarify decision-making powers and arrangements

4. New fit-for-purpose coordinating and planning mechanisms

5. Additional resourcing of public institutions responsible for climate change adaptation

6. New funding mechanisms and rules to minimize uncertainty and delays

1. Early engagement with the public and key stakeholders to build understanding of the problem and support for managed retreat

2. Provision of comprehensive risk-related information via multiple media in clear, accessible formats

3. Avoid public funding arrangements that may bias community preferences in favour of protection

4. Clarification of funding rules, including any assistance for residents adjacent to hazard areas

5. Robust and inclusive decision-making processes that address concerns that otherwise give rise to legal challenge

1. Reformed planning legislation so rules and procedures can be applied consistently and flexibly, and improved monitoring

2. New coordination mechanisms across levels of government

3. Active use of adaptive planning tools that avoid path dependency

4. Development of comprehensive strategies, plans and budgeting for each managed retreat with trigger points for adaptation decisions

5. Development and oversight of vacated land to enhance amenity values

1. New funding instruments and revenue sources for pre-emptive managed retreat, including long-term pre-funding arrangements

2. Co-funding arrangements that do not shift implementation of managed retreat to the weakest funder

3. Negotiated political multiparty agreements on public compensation arrangements to ensure consistency and stability over time

1. Targeted financial assistance

2. Risk pooling via public agencies

2. Provision of affordable housing in safe locations

The literature cited in this paper supports the constraints in Table 1 
level, coastal settings are also desirable places to live and people may have a short-term investment focus. Add to this, uncertainties over when to adapt, how to plan for changing risk and design funding frameworks (including the form and level of any compensation available for those facing property losses), public opposition to proposals for managed retreat exacerbates. These drivers of human behaviour confound decision-makers in the face of sea-level rise and increase the political incentives for elected officials to favour short-term visible fixes, rather than more prudent long-term strategies. Even where councils and communities have worked together to develop adaptation strategies that include managed retreat, implementation is constrained without robust planning and funding mechanisms [37].

Currently, most countries lack sound adaptation funding arrangements. Key weaknesses include inconsistent and unsystematic fiscal provisions, a focus on funding post-disaster managed retreat instead of pre-emptive measures, and a lack of prefunding for some of the expected costs of climate change adaptation (e.g. via dedicated funds [10]). Of significance is the current practice in many countries that favours the funding of structural defences that protect property in the short-term (e.g. seawalls, flood levees), rather than reducing long-term risk exposure. Such arrangements have two drawbacks. First, they give many property owners and residents a false sense of security from the 'levee effect' [38] encouraging further development in such areas which increases the residual risk. Second, they create a politically salient policy asymmetry: in short, they increase the public demand for protection, even in situations where the cost-effectiveness, technical viability and/or longterm utility of such measures is highly questionable.

\section{Public Compensation as an Implementation Mechanism}

There are competing principles and considerations regarding whether residents who will lose their property through managed retreat should be compensated and, if so, on what basis, to what extent and by what means $[10,39,40]$. Internationally, the level of, and eligibility for, public compensation varies greatly: in some cases, property owners are fully compensated based on a (pre-disaster) fair market value; in other cases, compensation provides for full replacement of a house/ apartment in a similar, but low-risk, neighbourhood; in yet other cases, such as the UK, there is little or no compensation currently available [41]. Other forms of public assistance may also be limited. For countries like the USA with wellestablished funding arrangements, compensation packages include relocation assistance, help for renters and additional targeted funding where there are large gaps between the value of at-risk properties and the cost of alternative accommodation. Underpinning these arrangements is a societal commitment to the proposition that citizens faced with unavoidable and uninsurable losses should be assisted so that they can move on with their lives while being properly housed.

Importantly, where public compensation is available, it often entails co-funding by national and sub-national agencies. However, such arrangements add to the policy complexity, contribute to delays and raise equity issues, not least because of the unequal resources and capabilities of sub-national governments [29, 42-44]. Local authorities are typically reluctant to fund or co-fund property buyouts due to fear of

- Setting precedents as climate change impacts worsen;

- Their financial resources being limited;

- Providing compensation to property owners raising politically sensitive issues around who gains and who pays; and

- The loss of properties reducing their income from property rates/taxes.

\section{Integrated Policy Frameworks}

To date, managed retreat as an adaptative response has often been poorly sequenced and integrated with related policy settings. For instance, in the USA some buyout programmes have not been coordinated with land-use planning, controls on development, the construction of housing and infrastructure investment (e.g. sea walls proposed in areas where all the dwellings are being vacated, removed or demolished) $[45$, 46]. This has resulted in ad hoc and inefficient investments in areas soon to be abandoned and a failure to provide adequate social infrastructure for communities. Furthermore, funding managed retreat is difficult because of the magnitude of the costs, the fact that timeframes extend well beyond normal electoral cycles, and the complexities associated with multi-level governance.

If pre-emptive managed retreat is to be undertaken competently, cost-effectively and equitably for the future, often in contexts of deep uncertainty, new national policy frameworks and planning processes will be essential as the number and scale of necessary retreats increase over the next 50 years. As the sea level continues to rise and rainfall becomes more extreme, managed retreat becomes inevitable and extensive modifications to current policy frameworks will be necessary, as will the uptake of fit-for-purpose decision processes and tools for managing the uncertain timing and magnitude of impacts.

\section{Use of Dynamic Adaptive Pathways Planning and Assessment for Managed Retreat Strategies}

For decision-making in coastal settings with a rising base sea level and in river floodplain settings facing uncertainty over 
the future incidence and magnitude of flooding, bespoke assessment, and planning and decision-analysis tools are required $[47,48]$. Such tools to promote informed decisionmaking within this context are beginning to gain traction in real-world coastal and riverine flooding case studies.

Adaptation to climate change, and sea-level rise in particular, require strategies that can evolve with changing coastal system dynamics and increasing risks while also addressing impacts already being felt even at the lowest levels of hazard [49]. This means decision tools need to be deployed that factor in widening uncertainties and changing risk profiles to build in the ability to change future pathways and enable timely and cost-effective decisions. Decision-making under deep uncertainty tools (DMDU) are increasingly being used to inform management strategies in a variety of complex decision contexts in many countries (e.g. transport, forestry, flood management, water infrastructure and coastal change settings) [47]. To socialise pre-emptive decision-making, serious games have been used to provide real-time feedback to players on their policy choices over a 100 -year timeframe $[50,51]$. This enables the future to be experienced and decisions modified under a range of scenarios, including surprises. Socioeconomic and policy scenarios have also been used to test the efficacy of signals and triggers for sequencing adaptation actions and policy options including managed retreat [52].

We now present four examples of novel research that applied dynamic adaptive tools to advance our understanding of how managed retreat can be assessed and implemented. These include the identification of the components of managed retreat and their sequencing, applying portfolios of pathways for retreat of water infrastructure, using a serious game to understand decision choices where managed retreat is an option, and application of a modified real options analysis in a flood-risk management and a coastal decision-making process. While these examples do not cover all the implementation gaps identified in the literature, they are novel because they use a dynamic adaptive approach suited to addressing uncertainty and changing risk over time. Currently, there are few such examples globally that specifically focus on implementation of managed retreat.

\section{Components for Implementing Managed Retreat}

To provide a structured way of thinking about pre-emptive managed retreat, Olufson [53] identified the different components of the retreat process (Table 2). This enables an end-toend managed retreat strategy to be developed. The combination, staging and timing of the different components in such a strategy depend on the local geographies (topography, tectonics etc.), and their societal and economic conditions. By identifying the components, a manageable process for staging the components (Fig. 1) is shown, which will be different for the components used and the timing of their implementation. This gives a systematic process for the responsible agencies and the community to work with that is unique to managed retreat as an adaptation option. It thereby addresses some of the constraints outlined in Section 2.

Community engagement is a significant phase of any decision-making process as it enables new options and information to be introduced, discussed and developed by stakeholders. A commitment by governance agencies to ongoing community seminars, workshops and discussion sessions can enable co-production of managed retreat as an adaptation option, along with other options (even if temporary), to be better understood and more readily accepted by coastal communities.

Planning and preparing for implementation of a managed retreat strategy requires the identification of options, the selection of adaptation actions and the identification of different pathways a retreat could take. This includes identifying thresholds, and trigger points for activating adaptation choices, planning and quick implementation of development restrictions and re-zoning to reduce legacy effects, and the development of programmes to monitor the predetermined signals and triggers to avoid intolerable adaptation thresholds defined by the community and responsible agencies [54].

Enabling investment to be carried out effectively when required includes property acquisition and/or compensation programmes, the development of alternative land for relocation, investments in new infrastructure and reduced investment in at-risk infrastructure.

Active retreat involves relocation, removal, or abandonment of private and public property, activation of covenants on property, and the relocation of public and private infrastructure (i.e. transport, water, telecommunications and other utility services). Active retreat is dependent on the first three components being completed as they comprise the supporting policies and mandate for effective implementation.

Clean-up and repurposing components include the demolition of remaining structures and services, rehabilitation of abandoned land (e.g. removal and treatment of septic tanks, removal of concrete, replanting of coastal vegetation), and the enhancement and maintenance of newly acquired public land to provide amenity value to the community.

Figure 1 shows an indicative set of pathways based on the component groupings in Table 2. These illustrate the various sequencing issues that managed retreat poses and the lengthy timeframes that will be required. Accordingly, the preparatory stages need to begin as early as possible to ensure communities and responsible agencies are ready for when the active retreat is required ahead of the pre-agreed adaptation threshold being reached. For example, suitable land must be available for relocating affected settlements. Equally, adequate funding mechanisms and statutory frameworks must be in place to facilitate the move [10]. 
Table 2 Managed retreat components, component groupings and stages [53]

\begin{tabular}{|c|c|c|}
\hline Grouping & Component & Description \\
\hline Community engagement & Community engagement & $\begin{array}{l}\text { - Community engagement/consultation on adaptation } \\
\text { options and implementation of managed retreat }\end{array}$ \\
\hline \multirow[t]{2}{*}{ Planning and preparing } & Planning & $\begin{array}{l}\text { - Plan/rule changes } \\
\text { - Planning for a reduction in infrastructure LoS } \\
\text { - Rebuilding and development restrictions }\end{array}$ \\
\hline & Monitoring & $\begin{array}{l}\text { - Monitoring } \\
\text { - Establishing trigger points }\end{array}$ \\
\hline \multirow[t]{3}{*}{ Enabling investment } & Property acquisition & $\begin{array}{l}\text { - Property acquisition offers and negotiations } \\
\text { - Development of covenants on property }\end{array}$ \\
\hline & New community investment & $\begin{array}{l}\text { - Acquisition of alternative land for relocation } \\
\text { - Development of new community facilities }\end{array}$ \\
\hline & Public infrastructure LoS reduction & - Reducing maintenance (LoS) of public infrastructure \\
\hline \multirow[t]{5}{*}{ Active retreat } & $\begin{array}{l}\text { Public infrastructure and structures } \\
\text { relocation }\end{array}$ & $\begin{array}{l}\text { - Replacement/redevelopment of public infrastructure elsewhere } \\
\text { - Relocation of critical-facility structures (schools, hospitals etc.) } \\
\text { - Relocation/replacement of community facilities (community halls, parks } \\
\text { etc.) }\end{array}$ \\
\hline & Privately owned infrastructure & - Private companies begin to reduce/remove/relocate their infrastructure \\
\hline & Covenants on property activated & - Covenants on property activated \\
\hline & Private property relocation/abandonment & $\begin{array}{l}\text { - Relocation/abandonment of residential and commercial property } \\
\text { - Providing temporary housing }\end{array}$ \\
\hline & Removal of marine structures & - Removal of marine structures \\
\hline $\begin{array}{l}\text { Clean-up and } \\
\text { repurposing }\end{array}$ & Clean-up & $\begin{array}{l}\text { - Demolition } \\
\text { - Land rehabilitation and maintenance } \\
\text { - Repurposing and zoning land-use }\end{array}$ \\
\hline
\end{tabular}

$\operatorname{LoS}$ level of service of infrastructure and utilities

A set of conditional signals (warnings) and trigger points (decision points), with pre-planned policies, procedures and actions activated as the trigger points are reached, enable timely decisions to be made that can avoid under or over investment due to uncertainties in timing of the damaging conditions [55]. The component actions can be used in different combinations depending on the local circumstances. The components can be grouped, staged and activated over time as

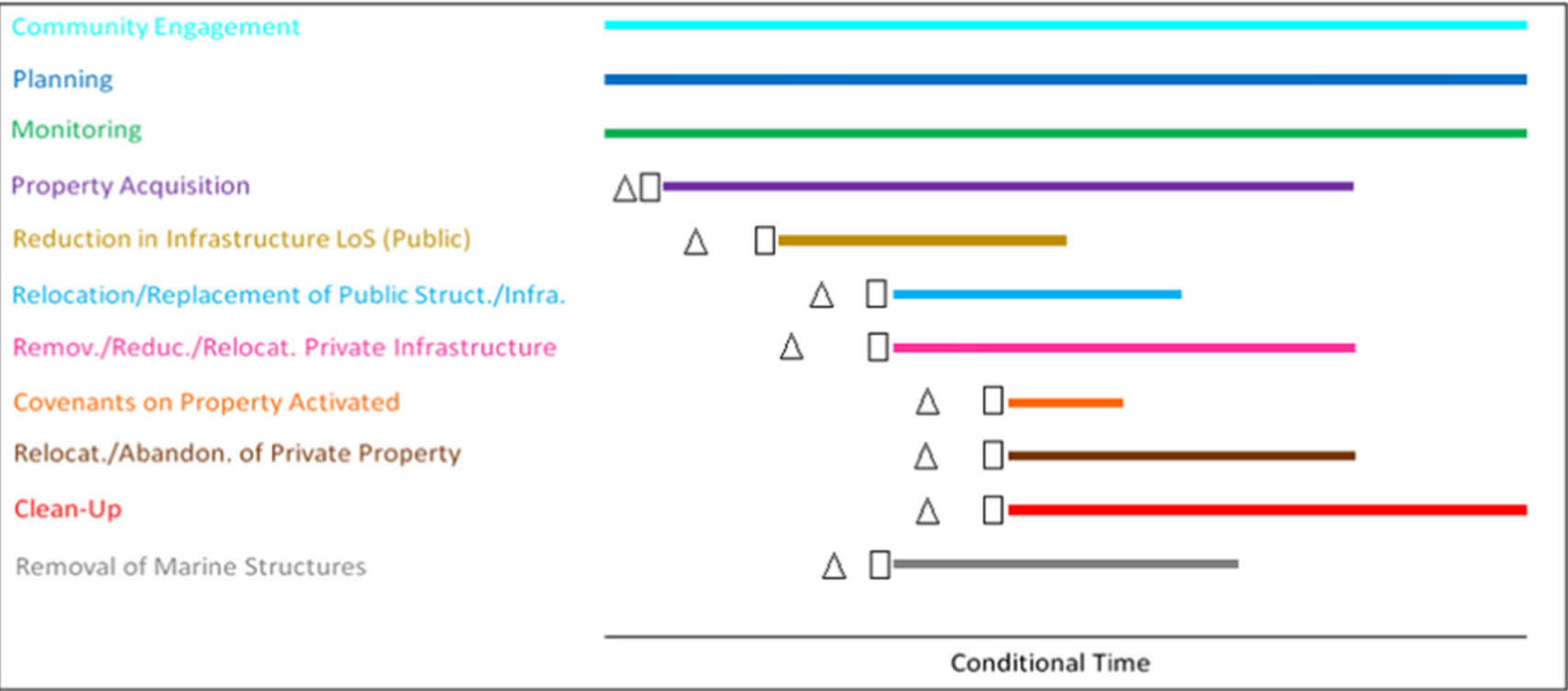

Fig. 1 An indicative staging of managed retreat components over time and in response to signals and triggers that reflect changed conditions over time. Triangles represent adaptation signals and rectangles represent decision points [53] 
the signals emerge and the triggers are reached [53], supported by engagement with communities and a staged funding strategy. Such staging and engagement can identify and enable distributional impacts and equity issues to be addressed for those affected and the wider community who may help pay for the retreat [56].

\section{An Integrated Set of Pathway Portfolios for Signalling Retreat of Water Infrastructure}

Kool [57] used an adaptive managed retreat approach based on dynamic adaptive pathways planning (DAPP), to show how wastewater and stormwater infrastructure could be spatially retreated across low-lying areas of Petone, near Wellington, New Zealand, as the sea rises. The DAPP approach showed that by separating the phasing (sequencing) of managed retreat from the selection of adaptation option pathways for the two water networks, retreat can be integrated spatially across sub-areas with different adaptation thresholds that are due to differences in topography (and hence emergence of risk). This can buy time when change in planning requirements is signalled early and adequate public engagement is undertaken. Provision of public amenity through water sensitive urban design can also contribute. Distinguishing adaptation thresholds for the system performance spatially, including exposed elements (e.g. pumping stations), resulted in a difference in retreat phasing by enabling a gradual or partial retreat in different spatially located areas (Fig. 2).

Adaptation portfolios were developed to maintain services until the specific threshold for retreat for each sub-area was reached. These portfolios contained a range of network adaptation options that together supported the managed retreat, while their individual implementation would have been less effective. Portfolios 1 and 2 (Fig. 2) protect the current drainage system until the retreat threshold is reached. Portfolios 3, 4 and 5 accommodate the existing drainage system and therefore require more transformative changes to the drainage system but are able to maintain services until a higher retreat threshold is reached. The implementation therefore depends on the area-specific retreat threshold. Water-sensitive urban design options (WSUD) were included in the adaptation portfolios to adapt the current drainage system, with the aim of creating amenity for the community by repurposing the area post-retreat. Such options can create extra capacity in the drainage system until it normalises after an extreme event, for example. However, WSUD usually require more space than conventional protection or accommodation adaptations. In largely urbanised areas, spatial constraints suggest that such repurposing would only be possible post-retreat. Nevertheless, by signalling amenity benefits from managed retreat, communities may be incentivised to stay together nearby post-retreat, if land and buildings are available.
Land use signals and planning changes were developed alongside retreat phases to signal the overall strategy and the timeframes within which change may occur. These include plan changes signalling limits to development using, for example, conditional rules (allowing development under new specifications), closed zoning (restricting new development), relocation (engage community and relevant stakeholders on relocation options and repurposing) and re-zoning (implement repurposing actions for the area). Signalling planning and land use changes could create more certainty for the community and relevant stakeholders, enabling them to anticipate changes in retreat phase and consequently infrastructure service levels.

If retreat were to be phased over different sea-level rise increments, the adaptation options could be implemented in the drainage system at the different spatial locations. By indicating the interactions between pathways in the system, conflicts and synergies arising from parallel implementation of options in the overall drainage system can be addressed. Synergies provide benefits from the pathway changes in adjacent areas, in particular by the WSUD portfolios. This is due to redundancy created in the drainage system by the retreat. Conflicts, on the other hand, indicate possible negative effects of a pathway on adjacent areas, identifying where further investigation is required. An example can be seen in Fig. 2. Drainage service duration was found to depend on when a retreat trigger is reached to avoid reaching an adaptation threshold, with pathway portfolios maintaining levels of service until the active retreat phase is initiated. Repurposing the area after active retreat by using WSUD measures can extend this threshold, therefore buying time for adjacent areas. This also allows for staging of expenditure, thus avoiding the perception that managed retreat costs all fall upfront. This perception is acting as a constraint upon agencies considering managed retreat. Including the community in the planning of the retreat process, especially for repurposing, could address some of the social barriers identified by Siders [45]. An interactive model to undertake quantitative stress testing of the adaptation thresholds within the system shown in Fig. 2 would provide a tool for stakeholders to use in the decision-making process.

\section{Testing Dynamic Adaptation Options Including Managed Retreat}

To investigate the viability of dynamic adaptive pathways planning (DAPP) to address river flood risk management issues, local government stakeholders took part in a serious game calibrated for the Lower Whanganui River in the north island of New Zealand, an area with an extensive history of high magnitude floods [30]. Participants simulated combinations of managed retreat, raised floor levels and new levees across management zones, to explore how near-term decisions might affect future flood damages under specified climate 


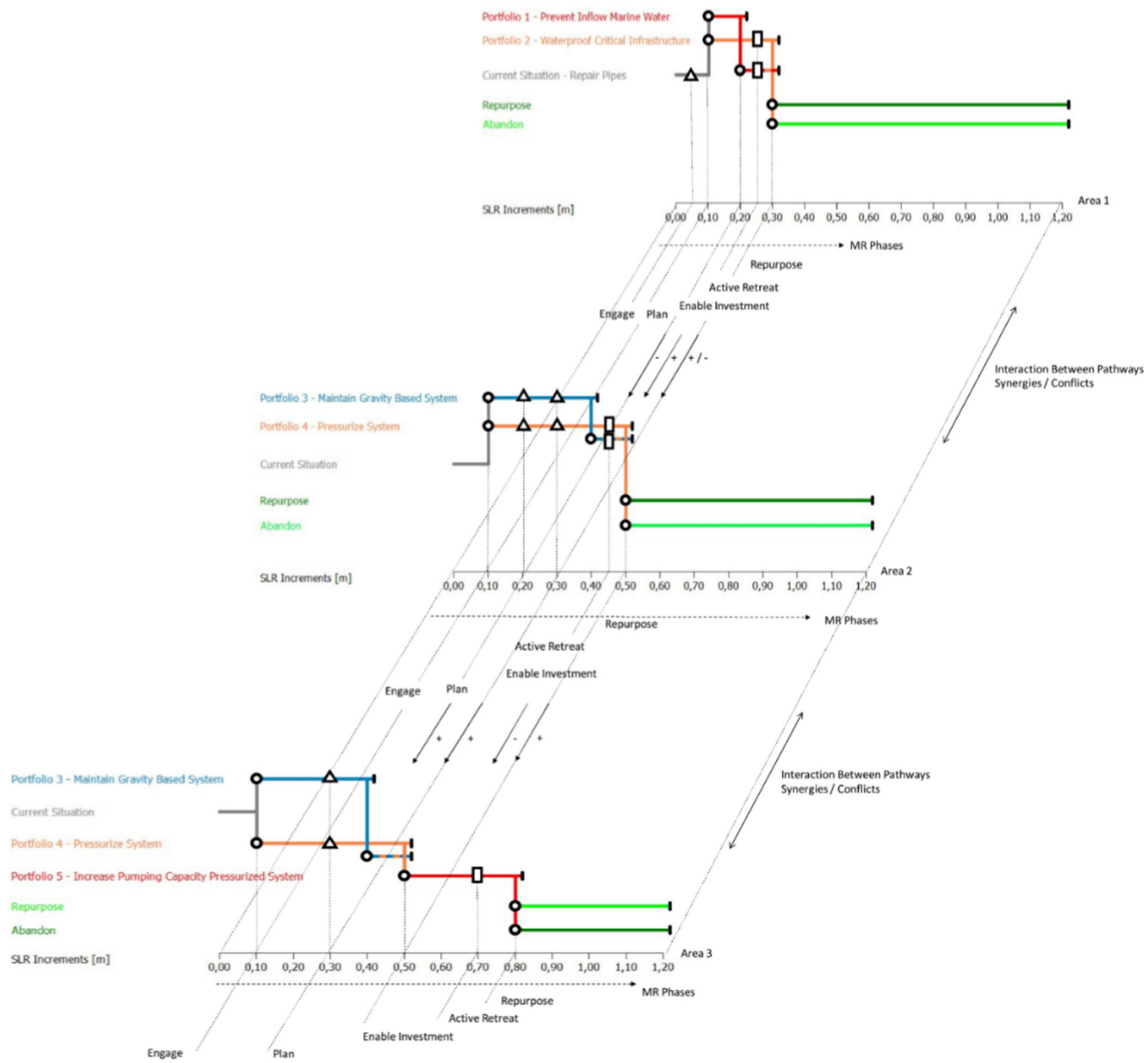

Fig. 2 Conceptual pathway portfolios illustrating synergies and conflicts between area-specific pathways

change scenarios. Over the course of five management rounds, two distinctive management styles were identified among participants:

- Proactive management-where participants developed a clear plan from the beginning, communicated this to communities and gradually implemented actions; and

- Reactive management - where participants responded to management problems as they occurred, using the flood damages from previous game rounds to leverage support for new interventions.

The final strategy adopted by the group relied heavily on reactive management (conventional approach), with participants being generally unwilling to alienate communities early in the session with unjustified spending [30]. This proved ineffective in the later stages of the game, where flood magnitudes became so severe that the participants were unable to react quickly enough to protect vulnerable people and assets, resulting in significant damage. While the game has not changed the immediate behaviours of the flood managers in situ, largely because a basic retreat plan for at-risk areas had previously been proposed, the game session gave players first-hand experience of the consequences of insufficient time to prepare and implement pathways options before intolerable adaptation thresholds are reached. Specific thresholds could be related to economic damage or return period shifts, or 
percentage changes in smaller but more regular mean annual floods [52].

The need to balance proactive and reactive management means that while climate change induced sea-level rise and river flooding may appear superficially similar from a hazard perspective, the challenges they pose for management authorities are quite different. Sea level is projected to rise faster by the end of this century, irrespective of the global emissions trajectory - but the incremental increase is tied directly to how emissions track [58]. Because of the clear trend in sea-level rise, proactive management approaches can be developed and deployed with some certainty, in conjunction with monitoring sea-level rise and the frequency of moderate flooding events and allowance for lead time [54]. In contrast, the climatechange signal or trends for localised river floods remain highly uncertain, given the weaker trends relative to climate variability, which may either favour well-supported reactive (post event) strategies [59] to minimise likely community resistance and unnecessary expense, or proactively encourage adaptation with a degree of precaution, for instance, to provide more room for the river at hydraulic pinch points. Maintaining a proactive-reactive planning balance presents institutional and technical barriers that river managers must overcome for river flood management plans to gain traction with stakeholders. Such barriers may range from a lack of long-term strategic policy and institutional buy-in, to limited or inaccurate models and data used to inform future flood impacts and resulting management plans [52].

Unlike other typical river management options (e.g. protective levees), the proactive-reactive balance for managed retreat must shift towards proactive planning due to two unique barriers rarely seen with other river management options:

- The logistical challenges of relocating large numbers of people, buildings and assets; and

- Community attachments to place.

As already discussed in Section 3.1, early engagement to overcome these barriers is desirable through adequate investment and community priming. However, while initial planning can be done proactively, the actual implementation of retreat can be staged in a reactive manner [53]. For river managers, maintaining this reactivity within a dynamic adaptive plan provides greater opportunities to learn more about the likely trajectory of major uncertainties (e.g. altered rainfall patterns) and build up understanding of climate variability in the interim [60]. Simultaneously, anxious stakeholders and communities can actively take part in retreat discussions and begin to take actions to mitigate personal psychological and economic impacts. Should river managers fail to adequately balance long-term planning with quick actions in river retreat, they risk trying to deliver too much too soon, or too little too late.

\section{Economic Tools alongside Dynamic Adaptive Pathways Planning}

Conventional economic assessment tools have limitations when used in situations of uncertainty and change as they run the risk of promoting path dependence and sunk costs. A tool that can address uncertainty is real options analysis (ROA), a costing method that enables the value of delay in implementing different options to be assessed, to reduce the chance of over- or under-investment in actions. This enables flexible implementation, depending on how the physical and socio-economic conditions evolve, and is therefore sensitive to community objectives over time. In New Zealand, there have been two notable applications of ROA combined with DAPP that formed part of decision processes. The first was in the completion of one of the largest flood control schemes in New Zealand, the Hutt River flood management plan, which was designed to manage a flood of 1:440 Annual Recurrence Interval, maintaining a flow of 2800 cumecs over 100 years. The second was in the development of a coastal hazards strategy for the east coast of the Hawke's Bay region.

The latter example from New Zealand used DAPP to analyse policy options and pathways under different future conditions alongside Multi-Criteria Decision Analysis (MCDA) in an extended engagement process with technical advisors and community panels using a modified ROA to cost pathways [61] based on the earlier application in a flood risk management context [62]. Using DMDU assessment and planning methods enabled a range of adaptation options to be identified, including protection, accommodation and retreat. These were assessed in a set of possible pathways before preferred pathways were decided. Several coastal units had managed retreat as an eventual option with temporary options in the near-term, such as groynes and breakwaters with beach nourishment, while one coastal unit had partial retreat for beach front properties and protection options for properties at a further distance from the beach. Several pathways over 100 years were developed for each coastal unit. This left the option open for eventual retreat to be brought forward in time. It enabled preparatory actions for managed retreat to be developed, e.g. land use planning constraints on further intensification of assets at the coast. To support future decision-making, a set of conditional signals and trigger points (decision points), and pre-planned policies, procedures and actions to be activated as the trigger points are reached are being developed, to avoid under- or over-investment decisions.

Combining DAPP with MCDA and ROA in a deliberative process with local councils and community panels [63] enabled the problem to be broken into actionable parts. It also defused contestation by starting with the familiar options and showing how pathways no longer deliver on objectives, and how alternative paths can. These applications opened up a space in which managed retreat was viewed by the community 
as inevitable. Managed retreat could then be considered and discussed [56] and in the earlier flood risk management case, implemented through property purchase well ahead of the active retreat actions.

The concept of a 'cut-off' probability is central to the way ROA was used in these cases. In most applications of ROA, the analyst is required to stipulate the probability of different future outcomes, with ROA then producing the investment strategy with the highest expected net benefit. In the two applications mentioned the question was reversed and asked under what probabilities two (or more) investment strategies yielded the same expected net benefit. That probability is termed the cut-off probability, representing the risk-neutral probability at which the statistically expected cost from over-investing in protection (i.e. spending more than turns out to be required for the desired degree of protection because the expected flood events did not materialise) is the same as the statistically expected cost of flood damage from underinvesting in protection (because flood damage turns out to be worse than expected).

The use of tools such as ROA in this modified form, alongside dynamic adaptive pathways options, enables the impacts of the timing of decisions or events to be revealed rather than requiring timing of decisions or events to be assumed in advance, thus addressing the uncertainty from changing risk profiles over time. It also enables decisions to be made about options in the short-term without locking in path dependencies, thus retaining flexibility to change pathways when conditions change before becoming intolerable. The modified ROA approach thus enabled options to be stress-tested for their sensitivity to climate scenario, discount rate, review date, costs and losses which enhanced the information councils had for decision-making where managed retreat was one of the options.

\section{Building Implementation Enablers}

Tools for assessing adaptation options and managed retreat strategies are necessary but not sufficient for enabling implementation of retreat strategies. The New Zealand examples set out in Section 3 revealed several factors necessary for effective implementation, including

- Available funding;

- Community co-production or engagement processes;

- Political leadership and an agreed decision-making framework;

- Land use planning and controls to prevent building back in at-risk areas;

- Protection of desired community outcomes such as amenity, recreational and cultural values; and
- Monitoring requirements embedded in implementation plans.

For these factors to be fit-for-purpose and sustainable in the face of escalating impacts and associated political pressures at the different levels of governance, several detailed issues require resolution. For example, the nature of the goals and principles that should inform managed retreat as an adaptation option; the allocation of the formal responsibilities for decision-making across the different tiers of government regarding where, when and how managed retreat should occur, and the necessary framework for effective inter-governmental coordination; the institutional and regulatory mechanisms, and policy tools needed to facilitate sound anticipatory governance, robust decision-making and competent implementation and importantly, who should pay for what, when and how, and whether any public compensation should be provided to those facing property losses (e.g. land, buildings and infrastructure and loss of place and social adjustment).

We suggest the following broad goals and principles to inform the development of coherent long-term strategies for pre-emptive managed retreat that can be implemented.

\section{Clear, Consistent and Transparent Policy Goals}

For effective adaptation to climate change, at least two goals are critical: long-term cost minimisation and equitable burden sharing. Pursuing these goals will entail efforts to limit costshifting between the different levels of government, minimise moral hazard that shifts burdens to others, and avoid funding arrangements that bias decision-making in favour of shortterm structural protection over pre-emptive staged retreat. By spreading the funding of managed retreat over multiple generations, including using pre-funding arrangements, intergenerational equity issues can be addressed, for example, like the funding of retirement income in some jurisdictions [11, 45, 64]. In reality, policy frameworks will reflect the national administrative traditions of risk pooling and social solidarity in response to natural disasters, prevailing fiscal constraints, relevant legal precedents and the treatment of private property rights. In many countries, the main burden will fall on taxpayers. However, not all countries have the fiscal resources to socialise private losses associated with managed retreat. For example, some least developed nations in Africa and Asia will face disproportionate impacts from sea-level rise (e.g. those with major river deltas) [25].

\section{Sound Anticipatory Governance}

Pre-emptive managed retreat requires the exercise of foresight and precaution when using adaptive decision-making. These in turn depend on reliable evidence; transparent risk assessments; the use of decision-making tools that are appropriate for 
conditions of deep uncertainty (e.g. DAPP and ROA); welldesigned and executed processes of public engagement; spatial planning with a long view; logistical capacity for addressing the many components of managed retreat; and clear, consistently applied policy processes that minimise uncertainty and disruption to the affected communities. These requirements are demanding and not easily met. Securing the necessary political mandate for an anticipatory approach to climate change adaptation is crucial but will often be challenging. It depends on whether the major political parties are committed to evidence-based policy-making and are willing to endorse a consensual, multiparty approach to the mitigation of long-term societal risks. Where such conditions are met, it should be possible to design and implement a range of substantive and procedural 'commitment devices' to facilitate pre-emptive managed retreat (e.g. in the form of discrete institutional mechanisms, planning processes and funding arrangements). Against this, where adversarial politics is the norm, political leadership is lacking or reliable scientific evidence is widely questioned, the quest for sound anticipatory governance is likely to falter.

\section{Robust Coordination between Governance Levels}

The effective implementation of pre-emptive managed retreat depends on robust coordination between levels of government and between agencies. For this to occur, the allocation of decision-rights across the tiers of government must be clear, with decision-rights and accountabilities linked to capability, especially funding. As noted earlier, some jurisdictions share the costs of retreat across different levels of government (e.g. local, state and federal, or local, regional and national). Cofunding spreads the fiscal costs across different groups of taxpayers, based on benefit ratios, thereby also diluting the associated political risks. But where co-funding is instituted, each tier of government must have the capacity to meet its share of the costs. Otherwise, implementing managed retreat may be jeopardised by the administrative unit with the least fiscal resources, causing delays, undermining public trust, and generating stress, litigation and social inequities. Equally, devolving administrative responsibilities for managed retreat requires the relevant authorities to have access to procedures for escalating the issue if their funding sources are limited (e.g. [9]). Also, local elected officials often face greater interest group pressures than their counterparts at the state or national levels, which can thwart effective implementation of managed retreat. Designing retreat funding models that minimize such risks is a priority.

\section{Reconceptualising Managed Retreat as a Strategic, First-Best Option}

To date, managed retreat has mostly been regarded as a last resort and as indicative of policy failure. This diminishes its utility in situations where relocating communities is inevitable and where near-term actions are necessary to avoid lock-in and path dependency from structural protection options. Retreat can also contribute to other public purposes. As Siders et al. [19] (p.761) argue, if retreat is fully integrated into a country's 'long-term development goals' and applied in a manner that is 'innovative, evidence-based, and contextspecific', it can serve as a vehicle for contributing to wider societal goals, such as greater fairness, sustainability, resilience and community revitalisation. How to do this effectively is a research gap.

\section{Public Compensation to Incentivise Managed Retreat}

Public compensation for private losses from implementing managed retreat remains highly controversial in many jurisdictions for reasons of fiscal cost, potentially regressive distributional impacts, the risk of compensation 'creep' and moral hazard, and philosophical preferences for private over social insurance. However, there are at least three reasons for considering public compensation. First, publicly funding protective structures, but not funding pre-emptive managed retreat, will increase citizens' demands for protection, even when not cost-effective, thus increasing costs. Second, effective implementation of pre-emptive managed retreat will likely require compulsory property acquisition. Typically, governments are legally obliged to compensate property owners in such circumstances. Third, private insurance will often be unavailable or unaffordable. Without compensatory arrangements, many communities will face large losses, with burdens falling disproportionately on the poorest citizens, thereby escalating the wider social, economic and political consequences of these impacts. Addressing these challenges will require funding frameworks with widely accepted and transparent statutory criteria. Understanding the possible range of compensatory mechanisms and other forms of public assistance is a significant gap in the managed retreat literature.

\section{Conclusion}

Managed retreat will become an increasingly crucial and unavoidable adaptation response in low-lying coastal and river floodplains due to sea-level rise and flooding from more intense rainfall. However, implementing pre-emptive managed retreat has proven to be the critical limiting step. Key constraints are a weak understanding by decision-makers of the dynamic nature of climate changes over time and how this affects communities differently from the past, what managed retreat comprises and how it can be staged over time. Compounding these constraints is the absence of many of the governance enablers for managing the retreat process, for example, sound anticipatory governance, adequate planning 
frameworks, robust funding arrangements, inclusive engagement processes and robust accountability mechanisms. Significant institutional and procedural reforms and the application of analytical tools and methods appropriate for the changing risk profiles are required for implementation of managed retreat as an adaptation option.

This paper has outlined the implementation issues associated with managed retreat and disaggregated the distinct components of managed retreat to show how it can be implemented in a systematic and manageable way. The novel application of decision-making tools that are tailored for changing risk situations are drawn from New Zealand based on the increasing use of such approaches globally [47]. We have highlighted some under-examined issues with respect to governance, institutional and funding arrangements. In doing so, we have outlined a series of goals and principles designed to enhance the ability of managed retreat to become a more acceptable and effective strategic adaptation response. Translating these goals into practice will require, among other things, competent political leadership that can build trust with affected communities and prepare them for the challenges ahead. It is also likely to depend on the capacity of the political system to secure broad multiparty agreement on the desirability of mitigating long-term risks and embed the necessary commitment devices to facilitate this goal. More extensive applied research is also required that can enhance our understanding of "what works', as well as the options available to improve existing planning, decision-making and funding frameworks.

Acknowledgements The authors thank the New Zealand Ministry of Business, Innovation and Employment research funding through the Resilience Science Challenge 'Living at the Edge' and 'Enabling Coastal Adaptation' programmes, and the Deep South Science Challenge 'Adaptive Tools' programme. R.G.B. was also supported by the NIWA Strategic Science Investment Fund CAVA 2004. Thanks also go to the Wellington, Hawkes Bay, Bay of Plenty, Canterbury and Horizons regional councils and to Wellington Water for their participation in the research. Comments from two anonymous reviewers strengthen the paper.

\section{Compliance with Ethical Standards}

Conflict of Interest On behalf of all authors, the corresponding author states that there are no conflicts of interest.

Open Access This article is licensed under a Creative Commons Attribution 4.0 International License, which permits use, sharing, adaptation, distribution and reproduction in any medium or format, as long as you give appropriate credit to the original author(s) and the source, provide a link to the Creative Commons licence, and indicate if changes were made. The images or other third party material in this article are included in the article's Creative Commons licence, unless indicated otherwise in a credit line to the material. If material is not included in the article's Creative Commons licence and your intended use is not permitted by statutory regulation or exceeds the permitted use, you will need to obtain permission directly from the copyright holder. To view a copy of this licence, visit http://creativecommons.org/licenses/by/4.0/.

\section{References}

1. Ghanbari M, Arabi M, Obeysekera M. Chronic and acute coastal flood risks to assets and communities in Southeast Florida. J Water Resour Plan Manag. Retrieved from. 2020. https://doi.org/10.1061/ (ASCE)WR.1943-5452.0001245.

2. Hauer M, Hardy RD, Kulp S, Mueller V, Wrathall D, Oppenheimer M, Clarke P A framework for classifying and assessing sea level rise risk. Preprint. Retrieved from https://doi.org/10.31235/osf.io/ tf6rj

3. Hinkel J, Lincke D, Vafeidis AT, Perrette M, Nicholls RJ, Tol RS, et al. Coastal flood damage and adaptation costs under 21st century sea-level rise. Proc Natl Acad Sci. 2014;111(9):3292-7. Retrieved from. https://doi.org/10.1073/pnas.1222469111.

4. Hinkel J, Aerts JC, Brown S, Jiménez JA, Lincke D, Nicholls RJ, et al. The ability of societies to adapt to twenty-first-century sealevel rise. Nat Clim Chang. 2018;8(7):570-8. Retrieved from. https://doi.org/10.1038/s41558-018-0176-z.

5. Kulp SA, Strauss BH. New elevation data triple estimates of global vulnerability to sea-level rise and coastal flooding. Nat Commun. 2019;10(1):1-12. Retrieved from. https://doi.org/10.1038/s41467019-12808-z.

6. Neal WJ, Bush DM, Pilkey OH (2017) Managed retreat. In: Finkl C, Makowski C (eds) Encyclopedia of coastal science. Encyclopedia of earth sciences series. Springer, Cham. Retrieved from https://doi.org/10.1007/978-3-319-48657-4.

7. Gibbs MT. Why is coastal retreat so hard to implement? Understanding the political risk of coastal adaptation pathways. Ocean Coast Manag. 2016;130:107-14. Retrieved from. https:// doi.org/10.1016/j.ocecoaman.2016.06.002.

8. OECD. (2019). Comparative approaches to sea-level rise: OECD country responses to tackling coastal risks.

9. Hanna C, White I, Glavovic B. The uncertainty contagion: revealing the interrelated, cascading uncertainties of managed retreat. Sustainability. 2020;12(2):736. Retrieved from. https://doi.org/10. 3390/su12020736.

10. Boston J, \& Lawrence J (2018). Funding climate change adaptation: the case for a new policy framework. Policy Quart, 14(2). Retrieved from https://doi.org/10.26686/pq.v14i2.5093.

11. Ellis E (2018). How should the risks of sea-level rise be shared? Deep South Challenge: Changing with our Climate. Retrieved from http://www.wpsanet.org/papers/docs/Ellis\%20WPSA\%202019. pdf. Accessed 16 June 2020.

12. Noy I (2020). Paying a price of climate change: who pays for managed retreats? Curr Climate Change Rep, pp.1-7. Retrieved from https://doi.org/10.1007/s40641-020-00155-x.

13. Collins M, Sutherland M, Bouwer L, Cheong S-M, Frölicher T, Combes HJD, Roxy MK, Losada I, McInnes K, Ratter B, RiveraArriaga E, Susanto RD, Swingedouw D, and Tibig L, 2019: Extremes, abrupt changes and managing risk. In: IPCC Special Report on the Ocean and Cryosphere in a Changing Climate [Pörtner H-O, Roberts DC, Masson-Delmotte V, Zhai P, Tignor M, Poloczanska E, Mintenbeck K, Alegría A, Nicolai M, Okem A, Petzold J, Rama B, Weyer NM (eds.).

14. Healy A, Malhotra N. Myopic voters and natural disaster policy. Am Polit Sci Rev. 2009;103(3):387-406. Retrieved from. https:// doi.org/10.1017/S0003055409990104.

15. Mortreux C, de Campos RS, Adger WN, Ghosh T, Das S, Adams $\mathrm{H}$, et al. Political economy of planned relocation: a model of action and inaction in government responses. Glob Environ Chang. 2018;50:123-32. Retrieved from. https://doi.org/10.1016/j. gloenvcha.2018.03.008.

16. White I, Haughton G. Risky times: hazard management and the tyranny of the present. International Journal of Disaster Risk 
Reduction. 2017;22:412-9. Retrieved from. https://doi.org/10. 1016/j.ijdrr.2017.01.018.

17. Gibbs MT (2020). The two-speed coastal climate adaptation economy in Australia. Ocean Coastal Manag, 190. Retrieved from https://doi.org/10.1016/j.ocecoaman.2020.105150.

18. Hino M, Field CB, Mach KJ. Managed retreat as a response to natural hazard risk. Nat Clim Chang. 2017;7(5):364-70.

19. Siders AR, Hino M, Mach KJ. The case for strategic and managed climate retreat: why, where, when and how should communities relocate? Science. 2019;365(6455):761-3. Retrieved from. https:// doi.org/10.1126/science.aax 8346

20. Turbott, C. (2006). Managed retreat from coastal hazards: options for implementation. Andrew Stewart Limited. Waikato Regional Council. Retrieved from https://www.waikatoregion.govt.nz/ assets/WRC/WRC-2019/tr06-48.pdf. Accessed 18 June 2020.

21. Fagan B (2013). The attacking ocean: the past, present and future of rising sea levels. Bloomsbury Publishing Plc, 265.

22. Nerem RS, Beckley BD, Fasullo JT, Hamlington BD, Masters D, Mitchum GT. Climate-change-driven accelerated sea-level rise detected in the altimeter era. Proc Natl Acad Sci. 115(2018, 9):20225. Retrieved from. https://doi.org/10.1073/pnas.1717312115.

23. Moftakhari HR, Salvadori G, Agha Kouchak A, Sanders BF, Matthew RA. Compounding effects of sea-level rise and fluvial flooding. Proc Natl Acad Sci. 2017;114(37):9785-90. Retrieved from. https://doi.org/10.1073/pnas.1620325114.

24. Ganguli P, Merz B. Extreme coastal water levels exacerbate fluvial flood hazards in North-Western Europe. Sci Rep. 2019;9(1):1-14. Retrieved from. https://doi.org/10.1038/s41598-019-49822-6.

25. Nicholls R, Adger W, Hutton C, \& Hanson S (2020). Ed. Deltas in the Anthropocene. Springer. Retrieved from https://doi.org/10. 1007/978-3-030-23517-8.

26. Rijke J, van Herk S, Zevenbergen C, Ashley R. Room for the river: delivering integrated river basin management in the Netherlands. Int J River Basin Manag. 2012;10(4):369-82. Retrieved from. https://doi.org/10.1080/15715124.2012.739173.

27. Vandenbeld A, \& MacDonald J (2013). Community acceptance of managed retreat in New Zealand. Clim Adapt Futur, pp.161. Retrieved from https://doi.org/10.1002/9781118529577.ch15.

28. Stive MJF, de Schipper MA, Luijendijk AP, Aarninkhof SGJ, van Gelder-Maas C, van Thiel de Vries JSM, et al. A new alternative to saving our beaches from local sea-level rise: the sand engine. $\mathrm{J}$ Coast Res. 2013;29(5):1001-8. https://doi.org/10.2112/ JCOASTRES-D-13-00070.1.

29. Mach KJ, Kraan CM, Hino, M, Siders AR, Johnston EM, \& Field CB. Managed retreat through voluntary buyouts of flood-prone properties. Sci Adv, (2019);5(10). Retrieved from https://doi.org/ 10.1126/sciadv.aax8995.

30. Hardcastle, M. (2019). Turbulent times - development of an accessible decision-support methodology to aid uncertain flood-based decision-making. University of Auckland E-Thesis. Retrieved from https://researchspace.auckland.ac.nz/handle/2292/47529. Accessed 18 June 2020.

31. Woodruff SC, Mullin M, \& Roy M. Is coastal adaptation a public good? The financing implications of good characteristics in coastal adaptation. J Environ Plan Manag, 2020 pp.1-20. Retrieved from https://doi.org/10.1080/09640568.2019.1703656.

32. Whakatane District Council. Awatarariki 'managed retreat' funding confirmed. 2019; July 17, 2019. Retrieved from https://www. whakatane.govt.nz/news/awatarariki-managed-retreat-fundingconfirmed.. Accessed 18 June 2020.

33. Reisinger A, Lawrence J, Hart G, \& Chapman R. From coping to resilience: the role of managed retreat in highly developed coastal regions of New Zealand. Clim Change Coast, 2014 pp.320-347 CRC press. Retrieved from https://doi.org/10.1201/b18053-18.

34. King D, Bird D, Haynes K, Boon H, Cottrell A, Millar J, et al. Voluntary relocation as an adaptation strategy to extreme weather events. Int J Disaster Risk Reduction. 2014;8:83-90. Retrieved from. https://doi.org/10.1016/j.ijdrr.2014.02.006.

35. Kousky C, Pratt J, \& Zeckhauser R. Virgin versus experienced risks. The Irrational Economist: Making Decisions in a Dangerous World, 2010 pp.99-106. Retrieved from https://www. researchgate.net/profile/John_Pratt6/publication/237505863 Virgin_Versus_Experienced_Risks/1inks/ 54d38dc20cf2501791824838/Virgin-Versus-Experienced-Risks. pdf. Accessed 18 June 2020.

36. Colliar J, \& Blackett P. Tangoio pathways Tangoio climate change adaptation decision model a process for exploring adaptation pathways for Tangoio Marae. Deep South Sci Challenge 2018;2018. Retrieved from https://www.deepsouthchallenge.co.nz/sites/ default/files/2018-11/Tangoio\%20NIWA\%20Client\%20report\% 20FINAL\%20Aug\%202018.pdf. Accessed 18 June 2020.

37. Ministry for the Environment and Hawkes Bay Regional Council. Case study: challenges with implementing the Clifton to Tangoio Coastal Hazards Strategy 2120. 2020 Retrieved from https://www. mfe.govt.nz/sites/default/files/media/Climate\%20Change/ challenges-with-implementing-the-Clifton-to-Tangoio-coastalhazards-strategy-2120-case-study.pdf. Accessed 18 June 2020.

38. Tobin GA. The levee love affair: a stormy relationship? 1. JAWRA J Am Water Resour Assoc. 1995;31(3):359-67. Retrieved from. https://doi.org/10.1111/j.1752-1688.1995.tb04025.x.

39. New Zealand Productivity Commission. (2019). Report on local government funding and financing.

40. Tombs BD, \& France-Hudson B (2018). Climate change compensation. Policy Q, 14(4).

41. Climate Change Committee. (2018). Managing the coast in a changing climate.

42. Freudenberg R, Calvin E, Tolkoff L, \& Brawley D (2016). Buy-in for buyouts: the case for managed retreat from flood zones. Lincoln Institute of Land Policy Cambridge, MA. Retrieved from https:// www.lincolninst.edu/sites/default/files/pubfiles/announce-buy-infor-buyouts-101611.pdf. Accessed 18 June 2020.

43. Freudenberg R, Calvin E, Tolkoff L, \& Brawley D. Buy-in for buyouts: three flood-prone communities opt for managed retreat. 2016, Retrieved from https://www.lincolninst.edu/sites/default/ files/pubfiles/buy-in-for-buyouts-071611.pdf. Accessed 18 June 2020.

44. Moore R, \& Weber A. Going Under: Long Wait Times for PostFlood Buyouts Leave Homeowners Underwater. 2019; Retrieved from http://repo.floodalliance.net/jspui/handle/44111/3165

45. Siders AR. Social justice implications of US managed retreat buyout programs. Clim Chang. 2019;152(2):239-57. Retrieved from. https://doi.org/10.1007/s10584-018-2272-5.

46. Craig RK. Coastal adaptation, government-subsidized insurance, and perverse incentives to stay. Clim Chang. 2019;152(2):21526. Retrieved from. https://doi.org/10.1007/s10584-018-2203-5.

47. Marchau VA, Walker WE, Bloemen PJ, \& Popper SW (2019). Decision making under deep uncertainty. Springer. Retrieved from http://link.Springer.Com/10.1007/978-3-030-05252-2.. Accessed 18 June 2020.

48. Hinkel J, Church JA, Gregory JM, Lambert E, Le Cozannet G, Lowe J, et al. Meeting user needs for sea-level rise information: a decision analysis perspective. Earth's Future. 2019;7(3):320-37. Retrieved from. https://doi.org/10.1029/2018EF001071.

49. Paulik R, Stephens S, Bell R, Wadhwa S, Popovich B. Nationalscale built-environment exposure to 100 -year extreme sea-levels and sea-level rise. Sustainability. 2020;12:1513.

50. Flood S, Cradock-Henry NA, Blackett P, \& Edwards P Adaptive and interactive climate futures: systematic review of 'serious games' for engagement and decision-making. Environ Res Lett, 2018;13(6). Retrieved from https://doi.org/10.1088/1748-9326/ aac1c6. 
51. Lawrence J, Haasnoot M. What it took to catalyse uptake of dynamic adaptive pathways planning to address climate change uncertainty. Environ Sci Pol. 2017;68:47-57. Retrieved from. https:// doi.org/10.1016/j.envsci.2016.12.003.

52. Lawrence J, Bell R, Blackett P, Stephens S, Collins D, CradockHenry N, et al. Supporting decision making through adaptive tools in a changing climate. Wellington: Deep South Challenge. Retrieved from; 2020. https://www.deepsouthchallenge.co.nz/ sites/default/files/2020-03/Supporting\%20decision\%20making\% 20 through $\% 20$ adaptive $\% 20$ tools $\% 20$ in $\% 20$ a $\% 20$ changing $\%$ 20climate $\% 20$ Practice $\% 20$ guidance $\% 20$ on $\% 20$ signals $\% 20$ and $\%$ 20triggers.pdf

53. Olufson S. (2019). Managed Retreat Components and Costing in a Coastal Setting. Retrieved from http://hdl.handle.net/10063/8359. Accessed 18 June 2020.

54. Stephens, S. A., Bell, R. G., \& Lawrence, J. (2018). Developing signals to trigger adaptation to sea-level rise. Environ Res Lett, 13(10). Retrieved from https://doi.org/10.1088/1748-9326/aadf96.

55. Haasnoot M, van't Klooster S, Van Alphen J. Designing a monitoring system to detect signals to adapt to uncertain climate change. Glob Environ Chang. 2018;52:273-85. Retrieved from. https://doi. org/10.1016/j.gloenvcha.2018.08.003.

56. Lawrence J, Bell R, Blackett P, Ryan E, \& Robichaux L From guidance to practice: the adaptation transition at the coast. J NZ Plan Instit, 2019;(Planning Quarterly 214). Retrieved from https:// www.resiliencechallenge.nz/wp-content/uploads/2019/09/ Lawrence-et-al.-2019-From-guidance-to-practice.pdf

57. Kool R. Preparing for sea-level rise. An adaptive managed retreat case study. In Partial Fulfilment of Masters of Engineering at Technical University of Denmark and Victoria University of Wellington, New Zealand. Resilience Science Challenge Coastal Sub-Theme Adapting to New Zealand's Dynamic Coastal Hazards;2020

58. Oppenheimer M, Glavovic B, Hinkel J, van de Wal R, Magnan A, \& Abd-Elgawad A Chapter 4: sea-level rise and implications for lowlying islands, coasts and communities. In: IPCC Special Report on the Ocean and Cryosphere in a Changing Climate Eds H. O. Pörtner, D. Roberts, V. Masson-Delmotte, P. Zhai, Y. Tignor, E. Poloczanska, Et Al. [in Press]. Retrieved from (2019); https://www. researchgate.net/profile/Alexandre_Magnan/publication/
336134630_Sea_Level_Rise_and_Implications_for_Low_Lying Islands_Coasts and Communities/links $/ 5 \overline{\mathrm{d}} 91 \mathrm{bf} 7545 \overline{8}$ $515202 \mathrm{~b} 749 \mathrm{f} 2 \mathrm{a} / \mathrm{Sea}-$ Level-Rise-and-Implications-for-Low-LyingIslands-Coasts-and-Communities.pdf. Accessed 18 June 2020.

59. Barnett J, Graham S, Mortreux C, Fincher R, Waters E, Hurlimann A. A local coastal adaptation pathway. Nat Clim Chang. 2014;4(12):1103-8. Retrieved from. https://doi.org/10.1038/ nclimate2383.

60. Haasnoot M, Kwakkel JH, Walker WE, ter Maat J. Dynamic adaptive policy pathways: a method for crafting robust decisions for a deeply uncertain world. Glob Environ Chang. 2013;23(2):485-98. Retrieved from. https://doi.org/10.1016/j.gloenvcha.2012.12.006.

61. Infometrics. Real Options Analysis of Strategies to Manage Coastal Hazard Risks: Southern Units J-L for Hawke's Bay Regional Council. 2017;Retrieved from https://hbcoast.co.nz/assets/ Document-Library/Other-documents/Real-Options-Analysis-ofStrategies-to-Manage-Coastal-Hazard-Risks-Southern-Units-J-L. pdf. Accessed 18 June 2020.

62. Lawrence J, Haasnoot M, McKim L, Atapattu D, Campbell G, \& Stroombergen, A. (2019). From theory to practice: a timeline of interventions by a change agent with the developers and users of dynamic adaptive policy pathways (DAPP). In: Marchau V, Walker W, Bloemen P (eds) Decision making under deep uncertainty: from theory to practice. Retrieved from https://www.springer.com/us/ book/9783030052515. Accessed 18 June 2020.

63. Lawrence J, Bell R, \& Stroombergen A. A hybrid process to address uncertainty and changing climate risk in coastal areas using dynamic adaptive pathways planning, Multi-Criteria Decision Analysis \& Real Options Analysis: A New Zealand Application. Sustainability Special Issue. 2019; Retrieved from https://doi.org/ 10.3390/su11020406

64. Kunreuther H, Pauly MV. Dynamic insurance decision-making for rare events: the role of emotions. Geneva Pap Risk Insur-Issues Pract. 2018;43(2):335. Retrieved from. https://doi.org/10.1057/ s41288-017-0068-x.

Publisher's Note Springer Nature remains neutral with regard to jurisdictional claims in published maps and institutional affiliations. 